\title{
Evaluation of Antioxidant Activity of the Selected frequently used Traditional Wild Medicinal Plants from Lakhimpur, Assam (India)
}

\author{
Victor Singh Ayam ${ }^{1}$ and Pinki Gogoi \\ Department of Botany, Rajiv Gandhi University, Rono Hills, Doimukh-791112, Arunachal Pradesh, India \\ ${ }^{1}$ For correspondence, E-mail: victor_ayamsingh@yahoo.com
}

[Received 05.12.2018; Revised 16.12.2018; Accepted 20.12.2018; Published 31.12.2018]

\begin{abstract}
North Eastern India is a very diverse area because of its unique types of flora as well as from different tradition and community. Terminalia arjuna, Cheilocostus speciosus and Clerodendrum glandulosum are three important wild medicinal plants of family Combretaceae, Costaceae and Lamiaceae respectively, used by most of the people of Assam as medicine to cure certain illness like cardiovascular diseases, jaundice, high blood pressure etc. The aim of the present study is to evaluate the antioxidant activity of these three plant samples. Cold maceration method in methanol was applied in the preparation of extract and antioxidant activity was determined using DPPH free radical scavenging method. IC50 (inhibition concentration) value was calculated for all sample. For comparison of total antioxidant activity pure ascorbic acid was taken as standard. The study shows the highest antioxidant activity by $T$. arjuna with IC50 value at $12.508 \mu \mathrm{g} / \mathrm{ml}$, while $C$. speciosus and C. glandulosum shows considerably lower antioxidant activity with $\mathrm{IC}_{50}$ value at $300.532 \mu \mathrm{g} / \mathrm{ml}$ and $205.086 \mu \mathrm{g} / \mathrm{ml}$.
\end{abstract}

Key words: Traditional medicinal plant, Antioxidant activity, $\mathrm{DPPH}, \mathrm{IC}_{50}$ value, Clerodendrum glandulosum, Cheilocostus speciosus, Terminalia arjuna

\section{INTRODUCTION}

Medicinal plants form the backbone of several indigenous traditional systems of medicine (Ramya et al. 2008). North-east India is known as the home of different people of different tradition and community and also home of diverse flora, from evergreen tropical forest to alpine forest. Assam is a part of the northeastern region of India with a high number of endemic flora and fauna (e.g. Messua assamica i.e. Sia nahar in Assamese). Annually different climatic condition is available in Assam; therefore, various types of plant species are found in this region. Though some region of Assam is comparatively developed yet natives in many other places were under poverty with weak purchasing power and depends everything on forests for their livelihood such as foods, medicines, fire-woods, etc. Various wild plants are used as medicines from ancient time. People of Assam specifically hold this ancient tradition of using wild plants as medicine till today. Various plants such as Acorus calamus, Centella asiatica, Pogostemon benghalensis, Hibiscus acetosella, Terminalia arjuna, Cheilocostus speciosus, Clerodendrum glandulosum etc. used traditionally as medicines against various diseases. Different plant parts produce pharmacologically active compounds like flavonoids, alkaloids, tannin, steroids, glycosides, phenols, fixed oils etc. (Sharma et al. 2008). Medicinal plants, a source of remedies, were widely used as alternative therapeutic tools for the prevention or treatment of many diseases 
(Kaur \& Mondal 2014). Antioxidants are considered as one of the important bioactive compounds on account of many health benefits along with their pivotal role in delaying oxidative rancidity of numerous food (Moharram \& Youssef 2014). Oxidation is a chain reaction that releases free radicals like reactive oxygen species (ROS) and reactive nitrogen species (RNS), some of which are very dangerous and toxic to human health. So, antioxidants are considered an essential element that should provide in our daily diet. Antioxidants are available in both natural and synthetic condition. Natural antioxidants are obtained from mainly various medicinal plants, vegetables etc. Medicinal plants are therefore investigated for their antioxidant properties, and the demand for natural antioxidants are increasing day by day (Peschel et al. 2006). Leaves of Clerodendrum glandulosum (Nefafu in Assamese), boiled vegetable of which is believed to control blood pressure (Bordoloi \& Borthakur 1997). Cheilocostus speciosus, a shady and moist growing wild plant the rhizome decoction of which is believed to cure jaundice (Lim, 2014), similarly believed by the local people of Assam. The water decoction of dried and powdered bark of Terminalia arjuna is also widely used by ethnic people of Assam for curing various heart-related diseases, and its bark-juice is used as cardiotonic by some people (Khandekar \& Pansare 2018). Since plants with medicinal properties were bound to show antioxidant activity, these three frequently used medicinal plants (Table 1) of the area have been subjected to antioxidant activity [PLATE - I].

\section{MATERIALS AND METHODS}

Collection of plant material: The samples (i.e. Clerodendrum glandulosum, Cheilocostus speciosus and Terminalia arjuna) were collected during August - October of 2017 from Lakhimpur area of Assam, India. Samples were then brought to the Department of Botany, Rajiv Gandhi University, Arunachal Pradesh for further analysis.

Table 1. Names of the selected plant species and their traditional medicinal uses.

\begin{tabular}{|l|l|l|l|}
\hline $\begin{array}{l}\text { Assames } \\
\text { e name }\end{array}$ & Botanical name & Family & $\begin{array}{l}\text { Traditional uses as } \\
\text { medicine }\end{array}$ \\
\hline Nefafu & $\begin{array}{l}\text { Clerodendrum glandulosum } \\
\text { Lindl. }\end{array}$ & Lamiaceae & $\begin{array}{l}\text { Boiled leaves consumed to } \\
\text { control high blood pressure }\end{array}$ \\
\hline $\begin{array}{l}\text { Jomlakh } \\
\text { uti }\end{array}$ & $\begin{array}{l}\text { Cheilocostus speciosus } \\
\text { (J.Koenig) C.D.Specht }\end{array}$ & Costaceae & $\begin{array}{l}\text { Rhizome extract is taken to } \\
\text { cure jaundice }\end{array}$ \\
\hline Arjun & $\begin{array}{l}\text { Terminalia arjuna } \text { (Roxb. ex } \\
\text { DC.) Wight \& Arn. }\end{array}$ & Combretaceae & $\begin{array}{l}\text { Aqueous extract } \\
\text { (decoction) from dried } \\
\text { powdered bark to control } \\
\text { blood sugar, juice from } \\
\text { fresh bark as cardio-tonic, } \\
\text { and to cure cough. }\end{array}$ \\
\hline
\end{tabular}

Preparation of extract: Extract for the detection of antioxidant activity was prepared in $100 \%$ methanol as solvent. Collected samples were washed properly and shade dried at room temperature. Dried samples were powdered and stored. Cold maceration method is used in extract preparation by allowing sample powder to mix with methanol. Methanol and ethanol have been proven as the effective solvent to extract phenolic compounds. After five to seven days, mixtures were filtered and filtrates were concentrated using rotary evaporator. And, now the extract is ready for further quantitative tests.

Quantitative test for determining antioxidant activity: For quantitative part DPPH (2,2-Diphenyl-1-picrylhydrazyl) free radical scavenging activity method was used. The process for determining free radical scavenging activity of plant extracts was measured 

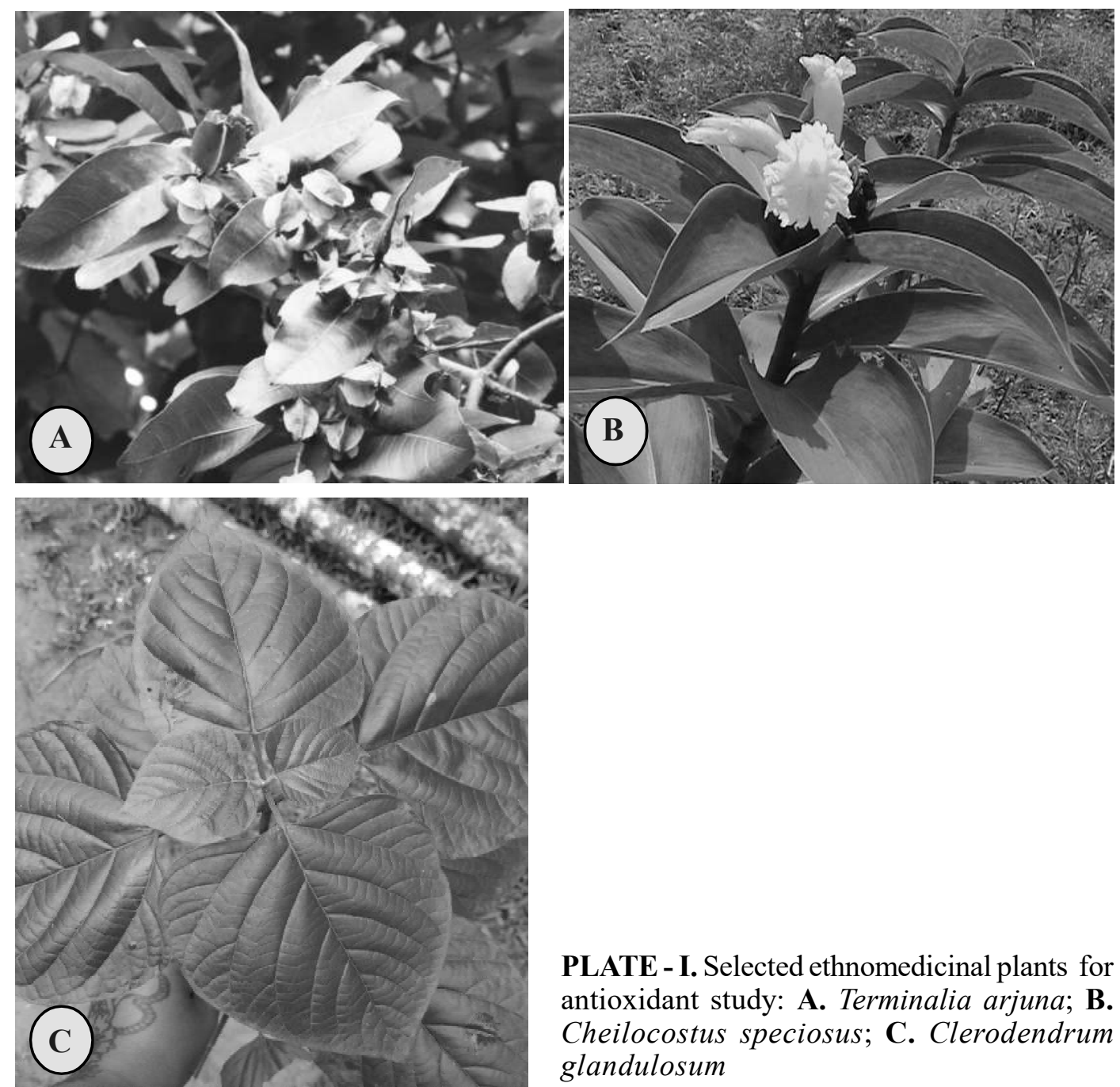

PLATE - I. Selected ethnomedicinal plants for antioxidant study: A. Terminalia arjuna; B. Cheilocostus speciosus; C. Clerodendrum glandulosum

by steps describing by Singh \& Asha (2017). DPPH scavenging method is based on the reduction of purple color of stable free radical DPPH into yellow color. Decreases in the absorbance of DPPH indicate an increase in the DPPH radical scavenging activity (Hazarika et al, 2012). Briefly, $1 \mathrm{mg}$ of extract was measured for each sample and seven different concentration of each sample extract was made mixing with the same solvent i.e. methanol, such as $1000,500,250,125,62.5,31.25,15.625 \mu \mathrm{g} / \mathrm{ml} .100 \mu 1$ of the sample from each concentration was pipette out in 96 well plates and add $200 \mu 1$ of $0.1 \mathrm{mM}$ DPPH solution (0.0039 gm DPPH powder mix with $100 \mathrm{ml}$ of methanol). Incubated for 30 minutes and absorbance was taken at $517 \mathrm{~nm}$ using Thermo-Scientific Multiskan Spectrophotometer. Methanol was used as the blank. Ascorbic acid was taken as standard. Four replicates were taken against each concentration to see the accuracy of the test. Instead of methanol distilled water was used as the solvent for ascorbic acid. A control solution (solvent + DPPH, without sample) was also used for the calculation of free radical scavenging activity of each replica of all three sample.

Statistical analysis: All statistical analysis was done by using excel. For free radical scavenging activity of the samples, calculations were done by following formula: 
DPPH scavenging activity $(\%$ of free radical inhibition $)=\left(A^{\prime}-\mathbf{A}\right) / \mathbf{A}^{\prime} * \mathbf{1 0 0}$

Where,

$$
\begin{aligned}
& \mathbf{A}^{\prime}=\text { absorbance of control } \\
& \mathbf{A}=\text { absorbance of plant samples }
\end{aligned}
$$

Graphs were drawn between concentration (X-coordinate) and inhibition \% (Y-coordinate) by logarithmic plotting for all and $\mathrm{IC}_{50}$ was calculated.

\section{RESULTS}

DPPH free radical scavenging activity- Among all three samples T. arjuna shows high scavenging activity against DPPH and found to have lower IC50 value $(12.508 \mu \mathrm{g} / \mathrm{ml}) \mathrm{com}$ pared to Cheilocostus speciosus and Clerodendrum glandulosum (Tables 2 \& 3), which shows IC50 value at $300.532 \mu \mathrm{g} / \mathrm{ml}$ and $205.086 \mu \mathrm{g} / \mathrm{ml}$ respectively. IC50 (inhibition concentration) is that concentration at which $50 \%$ of the free radicals will be inhibited by any source of antioxidant. Lower the IC50 value, higher will be the antioxidant activity of any sample. Being a pure antioxidant ascorbic acid (standard) shows IC50 at $7.038 \mu \mathrm{g} / \mathrm{ml}$ concentration. Thus, present investigation shows that Terminalia arjuna have the high amount of antioxidant activity among all tested samples, because it has close IC50 value with the standard ascorbic acid (Table 4). Like standard ascorbic acid, T. arjuna also shows its scavenging power at a very low concentration (Figure 2).

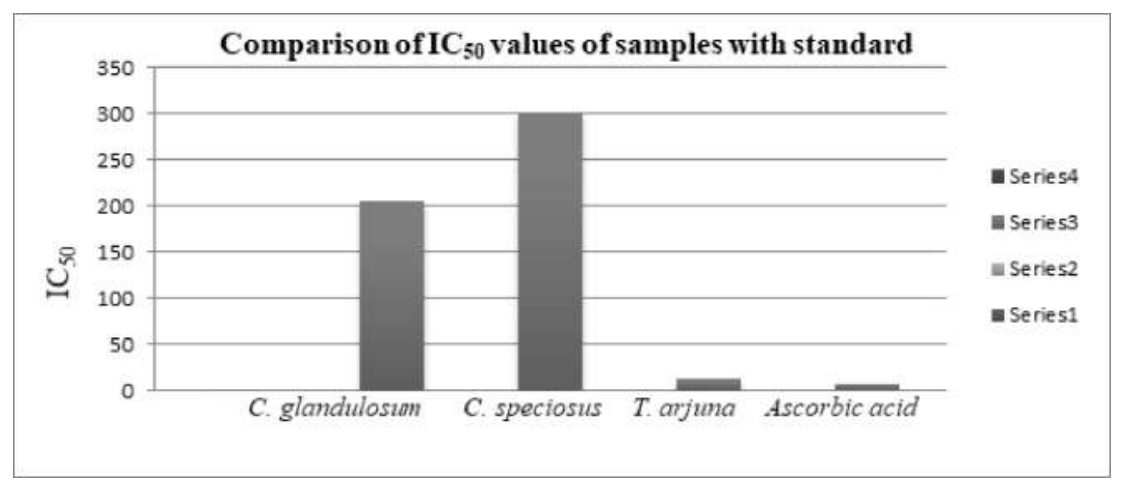

Figure 2. DPPH scavenging activity of samples v/s standard in terms of IC50 values.

Table 2. DPPH free radical scavenging activity of methanol extract of $T$. arjuna (bark) and of standard ascorbic acid at different concentrations

\begin{tabular}{|l|l|l|}
\hline $\begin{array}{c}\text { Concentrati } \\
\text { on }(\boldsymbol{\mu g} / \mathbf{m l})\end{array}$ & $\begin{array}{c}\text { Inhibition \% of } \\
\text { ascorbic acid }\end{array}$ & $\begin{array}{c}\text { Inhibition \% of } \\
\boldsymbol{T} \text {. arjuna }\end{array}$ \\
\hline 1.562 & $10.981 \pm 3.008$ & $5.348 \pm 1.837$ \\
\hline 3.125 & $21.538 \pm 0.829$ & $13.371 \pm 2.710$ \\
\hline 6.250 & $43.289 \pm 1.285$ & $22.699 \pm 1.481$ \\
\hline 12.50 & $82.918 \pm 1.141$ & $46.517 \pm 0.655$ \\
\hline 25.00 & $93.952 \pm 1.154$ & $72.699 \pm 2.077$ \\
\hline 50.00 & $95.172 \pm 0.659$ & $93.657 \pm 0.469$ \\
\hline 100.00 & $95.928 \pm 0.871$ & $95.584 \pm 0.215$ \\
\hline
\end{tabular}


Table 3. DPPH free radical scavenging activity of methanol extracts of leaves of $C$. glandulosum and C. speciosus

\begin{tabular}{|l|l|l|}
\hline $\begin{array}{l}\text { Concentration } \\
(\boldsymbol{\mu g} / \mathbf{m l})\end{array}$ & $\begin{array}{c}\text { Inhibition \% of } \boldsymbol{C} . \\
\text { glandulosum }\end{array}$ & $\begin{array}{c}\text { Inhibition \% of } \\
\text { C. speciosus }\end{array}$ \\
\hline 15.62 & $4.262 \pm 1.045$ & $7.453 \pm 0.968$ \\
\hline 31.25 & $9.207 \pm 0.754$ & $10.290 \pm 1.001$ \\
\hline 62.50 & $16.368 \pm 0.426$ & $11.900 \pm 0.961$ \\
\hline 125 & $28.474 \pm 0.378$ & $19.607 \pm 1.263$ \\
\hline 250 & $49.702 \pm 0.546$ & $36.928 \pm 1.677$ \\
\hline 500 & $80.008 \pm 0.295$ & $69.198 \pm 3.113$ \\
\hline 1000 & $86.615 \pm 0.403$ & $80.294 \pm 0.570$ \\
\hline
\end{tabular}

Table 4. $\mathrm{IC}_{50}$ values of tested samples with the standard

\begin{tabular}{|l|l|}
\hline Samples & $\begin{array}{l}\text { IC } \mathbf{5 0} \text { value } \\
(\boldsymbol{\mu g} / \mathbf{m l})\end{array}$ \\
\hline T. arjuna & 12.508 \\
\hline C. glandulosum & 205.086 \\
\hline C. speciosus & 300.532 \\
\hline Ascorbic acid (standard) & 7.038 \\
\hline
\end{tabular}

\section{DISCUSSION}

Plants have always been a rich source of phytochemicals, because of the presence of several biologically active compounds. The medicinal property of a plant depends on the presence of various secondary metabolites such as phenolics, terpenoids or alkaloids (Swargiary et al, 2016). Flavonoids, for instance, are a secondary metabolite that exhibits tremendous medicinal property including antioxidant, anticancer, antibacterial etc. (Kumar \& Pandey 2013). The present study revealed that the tested plant samples have scavenging power against stable DPPH radicals and proves that they have antioxidant potential suggesting the possible presence of important phytochemicals. The T. arjuna shows the highest antioxidant activity with the least $\mathrm{IC}_{50}(12.508 \mu \mathrm{g} / \mathrm{ml})$, which is similarly, recorded by M. Shahriar et al, 2012 from the bark of T. arjuna using various solvent extracts. The $\mathrm{IC}_{50}$ of $C$. glandulosum is comparatively higher $(205 \mu \mathrm{g} / \mathrm{ml})$, a closely similar value of the $\mathrm{IC}_{50} 168.89 \mu \mathrm{g} / \mathrm{ml}$ was reported by Doley Pradip et al, 2016 and the antioxidant potential of the plant was also reported by Sanjay Jagtap et al, 2014. The $\mathrm{IC}_{50}$ of $C$. speciosus is comparatively highest $(300 \mu \mathrm{g} / \mathrm{ml})$ which is similarly reported as medium - high by Jha et al. (2010).

\section{Conclusion}

From the present study, it can be concluded that T. arjuna, C. glandulosum, and $C$. speciosus show the antioxidant activity in descending order of $T$. arjuna $\gg C$. glandulosum $>C$. speciosus. This study justifies the use of these wild plants by ethnic people in their health benefits. The presence of antioxidant activity of these plants shows the potency of these tested plants to prepare medicines and to use as a source of competent natural antioxidant. 


\section{Acknowledgments}

The authors are thankful to the Centre with Potential for Excellence in Biodiversity (CPEBII), Rajiv Gandhi University, Arunachal Pradesh for providing the instrumentation facility.

\section{LITERATURE CITED}

Bordoloi, B. \& Borthakur, S.K. 1997. Botanical identity of 'Phuinum' a folk Remedy for hypertension. BMEBR. 18 (1): 18 - 29.

Doley, P.; Singh, A.V.; Devi, N.M.; Singh, Ch.B.; thokchom, A. 2016. Reverse phase HPLC estimation of antioxidants and antimicrobial activities of Clerodendrum colebrookianum Walp. J. Pharmacog. Phytochem. 5(3): 199 - 205.

Hazarika, N.; Singh, P.; Hussain, A.; Das, S. 2012. Phenolics content and antioxidant activity of crude extract of Oldenlandia corymbosa and Bryophyllum pinnatum. Res. J. Pharma. Biol. Chem. Sci. 3(2): 297.

Jagtap, S. \& Satpute, R. 2014. Phytochemical screening and antioxidant of rhizome extract of Costus speciosus (Koen) J.E. Smith. J. Acad. Indust. Res. 3(1): 40 - 47.

Jha, M.K.; Alam, M.B.; Hossain, M.S.; Islam, A. 2010. In vitro antioxidant and cytotoxic potential of Costus speciosus (Koen.) Smith rhizome. Intn. J. Pharmac. Sci. Res. 1(10): $138-144$.

Kaur, S. \& Mondal, P. 2014. Study of total phenolic and flavonoid content, antioxidant activity and antimicrobial properties of medicinal plants. J. Microbio. Exper. 1(1): $23-28$. DOI: 10.15406/jmen.2014.01.0000523-28.

Khandekar, S.B. \& Pansare, T.A. 2018. Ayurvedic and modern aspects of Arjuna (Terminalia arjuna): An overview. World J. Pharmac. Res. 7(15): 1064 - 1091.

Kumar, S. \& Pandey, A.K. 2013. Chemistry and biological activities of flavonoids: An overview. Sci. World J. 2013: 1 - 16. Article ID 162750.

Lim, T.K. 2014. Cheilocostus speciosus. In: Edible Medicinal and Non-Medicinal Plants. Springer, Dordrecht. Pp. 712 - 715. DOI: https://doi.org/10.1007/978-94007-7395-0_52. Print ISBN978-94-007-7394-3, Online ISBN978-94-007-7395-0.

Moharram, H.A. \& Youssef, M.M. 2014. Methods for determining the antioxidant activity: A review. Alex. J. Fd. Sci. \& Technol. 11(1): $31-42$.

Peschel, W.; Sanchez-Rabaneda, F.; Dieckmann, W. \& Gartzia, I. 2006. An industrial approach in the search of natural antioxidants from vegetable and frutits wastes. Food Chem. 97: $137-150$.

Ramya, S.; Govindaraji, V.; Navaneetha, K.K. \& Jayakumararaj, R. 2008. In vitro evaluation of antibacterial activity using crude extracts of Catharanthus roseus L. (G.) Don. Ethnobot. Leafl. 12: 1067 - 1072.

Shahriar, S; Akhter, S; Hossain, M.I.; Haque, M.A.; Bhuiyan, M.A. 2012. Evaluation of in vitro antioxidant activity of bark extract of T. arjuna. J. Med. Pl. Res. 6(39): 5286 - 5298.

Sharma, A.; Shankar, C.; Tyagi, L.; Singh, M. \& Rrao, C. 2008. Herbal Medicine for Market Potential in India: An Overview. Acad. J. Pl. Sci. 2: 26-36.

Singh, A.V.; Hage, A. 2017. Antioxidant activity of Terminalia bellirica (Gaertn.) Roxb. of Tawang, Arunachal Pradesh, India. J. Bio. 4(2): 65 - 72.

Swargiary, A.; Daimari, A.; Daimari, M.; Basumatary, N.; Narzary, E. 2016. Phytochemicals, antioxidant and anthelmintic activity of selected traditional wild edible plants of lower Assam. Indian J. Pharmaco. 48: 418 - 423. 